\title{
The Relationship Between the Level of Copper, Lead, Mercury and Autism Disorders: A Meta-Analysis
}

This article was published in the following Dove Press journal: Pediatric Health, Medicine and Therapeutics

\author{
Hamed Jafari \\ Mohammadabadi ${ }^{1, *^{*}}$ \\ Aryoobarzan Rahmatian ${ }^{2, *^{*}}$ \\ Fatemeh Sayehmiri ${ }^{3}$ \\ Mohammad Rafiei (iD) ${ }^{4}$ \\ 'School of Medicine, Shiraz University of \\ Medical Sciences, Shiraz, Fars, Iran; \\ ${ }^{2}$ Faculty of Medicine, llam University of \\ Medical Sciences, Ilam, Iran; ${ }^{3}$ Student \\ Research Committee, School of \\ Medicine, Shahid Beheshti University of \\ Medical Sciences, Tehran, Iran; \\ ${ }^{4}$ Department of Biostatistics and \\ Epidemiology, Arak University of Medical \\ Sciences, Arak, Iran
}

*These authors contributed equally to this work
Correspondence: Mohammad Rafiei Department of Biostatistics and Epidemiology, Arak University of Medical Sciences, Arak 3819693345, Iran Tel +981988637445

Email rafeie@arakmu.ac.ir
Background and Objectives: There is a likelihood of a possible relationship between the concentrations of copper, lead, and mercury and autism. The present review was carried out to determine the relationship between the concentrations of these elements and autism by meta-analysis.

Methods: In this study, searching Scopus, PubMed, and Science Direct databases, 18 articles conducted in different countries from 1982 to 2019 were collected. Studies' heterogeneity was investigated using the $\mathrm{I}^{2}$ index. The data were analyzed using $\mathrm{R}$ and STATA software.

Results: In these 18 studies, 1797 patients (981 cases and 816 controls) aged 2 to 16 years were examined. Concentration of the samples (blood, hair, and nails) for both case and control groups was evaluated. There was no significant relationship between copper concentration and autism (SMD (95\% CI): 0.02 (-1.16,1.20); $\left.\mathrm{I}^{2}=97.7 \% ; \mathrm{P}=0.972\right)$; there was a significant relationship between mercury concentration and autism (SMD (95\% CI): 1.96 (0.56,3.35); $\left.\mathrm{I}^{2}=98.6 \% ; \mathrm{P}=0.006\right)$; there was also a significant relationship between lead concentration and autism (SMD (95\% CI): 2.81 (1.64,3.98); $\left.\mathrm{I}^{2}=97.8 \% ; \mathrm{P}=0.000\right)$.

Conclusion: There is, nevertheless, a significant relationship between mercury concentration and autism. Thus, the concentration of mercury can be listed as a pathogenic cause (disease-causing) for autism.

Keywords: autism, copper, lead, mercury, meta-analysis

\section{Introduction}

Autism is a developmental disorder of social relations which is determined through individuals' abnormal communicative and verbal behaviors. Symptoms of this disorder occur before the age of three, and its etiology is still unknown. ${ }^{1-3}$ This disorder is more prevalent in boys than in girls and several studies showed a strong genetic background to the appearance of autism spectrum disorders (ASD). ${ }^{3}$ This disorder affects the normal brain development in different ways and causing some symptoms related to Difficulty in social interaction and communication skills. According to the studies carried out in this area, it is suggested that mercury and other toxic elements are involved in the pathogenesis of autism. ${ }^{4}$ Similar effects have also been mentioned for essential minerals and trace elements in the development of autism spectrum disorder. ${ }^{5}$ Compared with adults, children are more exposed to environmental toxic elements and the rate of absorption of such elements are higher in children. On the other hand, the chance of warding off 
elements' toxicity in children is less than adults. ${ }^{6}$ The study was done by Lonsdale et al confirms the relationship between heavy metals' toxicity and the risk of mental disorders. ${ }^{7}$ In a study by Priya et al, the researchers were able to prove the relationship between copper concentration and severity of autism disorders, examining the samples of hair and nails of the children with autism. ${ }^{8}$ Metals' biological effects are associated with their chemical properties, ${ }^{9}$ suggesting that excessive metal exposure can cause brain abnormalities around the world. ${ }^{10}$ Mercury is considered as a risk factor for autism ${ }^{4}$ since, according to previous studies, it has been recognized as a neurotrophic toxin. ${ }^{11}$ Reduction in mercury content in hair ${ }^{12}$ and teeth ${ }^{13}$ of the children with autism aroused the low disposal of mercury hypothesis. Blaurock-Bush et al found that heavy metals are effective in the development of autism disorder. ${ }^{14}$ The role of mercury in the pathogenesis of autism has also been proven in other studies. ${ }^{2,4,15}$ Copper is considered as one of the metals essential for cell metabolism, and it plays an important role in the oxidationreduction reaction. ${ }^{15}$ Lakshmi Priya et al observed that copper level in children with autism corresponded with the severity of autism disorder in a way that a higher level of copper was found in hair and nail samples of the children with less severe symptoms of autism than those of children with moderate and severe symptoms. ${ }^{16}$ The neurotoxic effects of copper include depression, irritability, fear, unrest, as well as learning and behavioral disorders. ${ }^{17}$ Considering the previous studies on the relationship between heavy metals and autism, for validating their results, it seems necessary that a meta-analysis study be conducted to determine the authenticity or lack of relationship between the concentrations of copper, lead, and mercury and autism and to provide a reliable pattern in the field for the researchers and planners. The present study aimed to determine the relationship between the concentration of copper, lead and mercury and autism using meta-analysis and systematic review.

\section{Methods}

\section{Data Sources and Search Strategy}

This article was written according to the PRISMA guidelines. Study protocol N/A. Using a systematic review, the present study was carried out to determine the relationship between the concentration of copper, lead, and mercury and autism. To collect the data, the articles published in national and international journals as well as presentations and theses in national and international electronic and nonelectronic databases, such as SID, Magiran, Irandoc, Iranmedex, PubMed, Embase and Scopus were used. The keywords used to find the articles included autism, copper, mercury, lead, heavy elements, and toxic elements. English equivalents of these keywords were used to search the international databases to scan through all the possible combinations of keywords. Having studied all the abstracts, unrelated papers and articles were removed, and all potential papers and articles were identified to be studied in full text.

\section{Study Selection (Inclusion and Exclusion Criteria)}

All cross-sectional that measured amount of copper, lead and mercury with autism were selected. The main inclusion criteria for the studies was referring to the relationship between the elements and autism. Study selection was carried out based on an article review in three stages: title, abstract and full text. All of the included studies investigated the relationship between the elements and autism. Studies were excluded from the analysis for any of the following reasons: studies with insufficient information, non-epidemiological studies, non-cross-sectional studies, and studies on the effects of other elements on autism. Review studies, congress summaries, studies published in languages other than Persian and English, meta-analyses and systematic studies as well as reduplicated publication of the same studies were also excluded from the analysis. The researcher first collected all papers on the relationship between the elements and autism and then prepared a list of the abstracts. At this point, 84 articles in the title of which the concentration of elements (copper, mercury, and lead) and autism had been used entered the preliminary list. Reviewing the reference lists of the articles, 11 other articles also entered the study. That is, a total of 95 articles entered the study. Then, all of the articles were independently and systematically reviewed, 38 of which were excluded from the study due to reduplication. The full text of 57 articles was evaluated, 39 of which were also excluded from the study (13 studies due to lack of reference to the type of criteria used; 18 studies due to their low quality; and 8 studies due to lack of access to the full-text of the articles). Eventually, 18 articles were selected as appropriate to be included in the meta-analysis (Figure 1). 


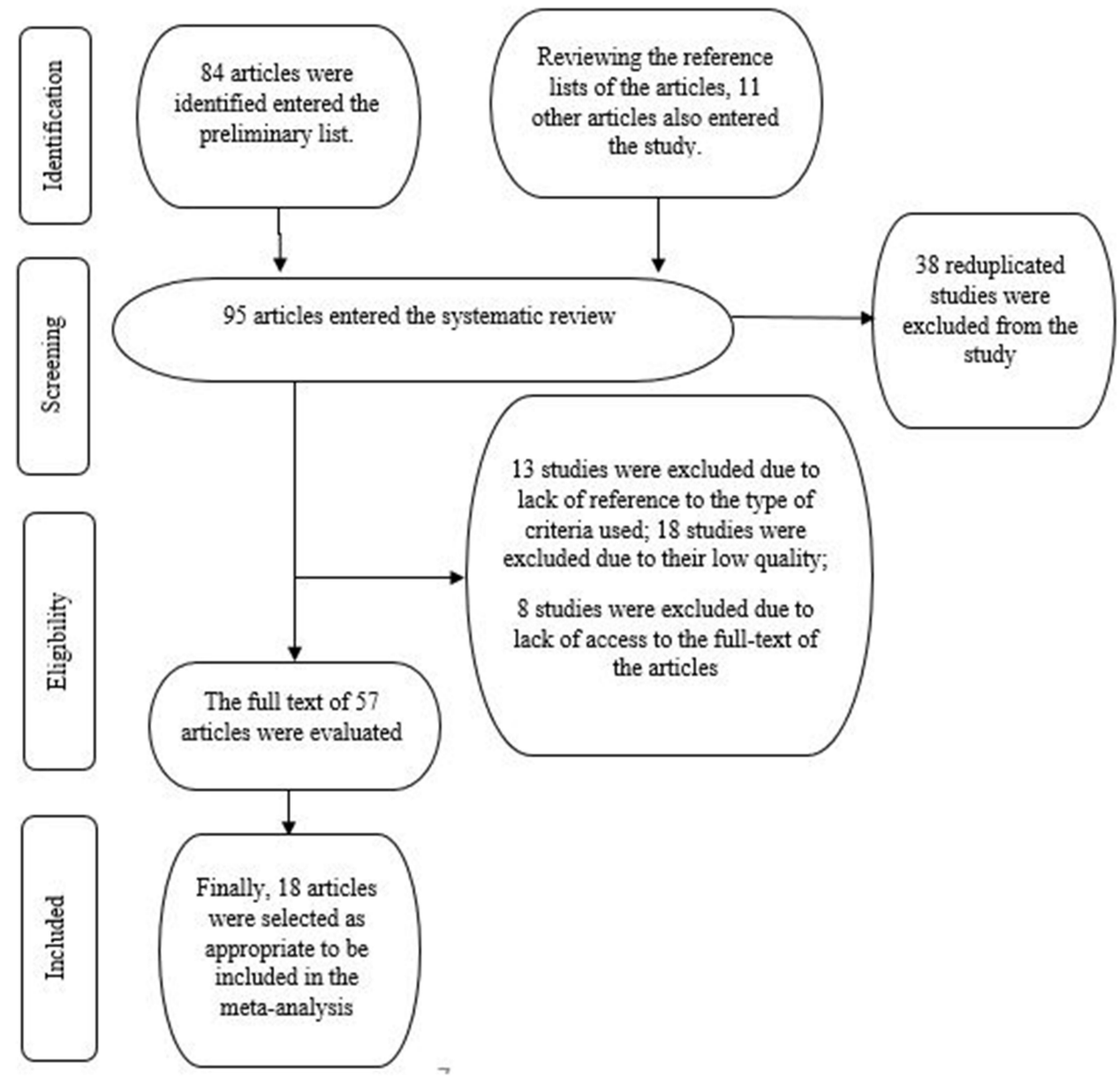

Figure I Flowchart for inclusion of the studies in the systematic review and meta-analysis.

\section{Data Extraction}

Having selected high-quality articles, a checklist of the necessary information for all the preliminarily evaluated studies was prepared for the final evaluation. Accordingly, in this study, 21 articles in which random sampling was used to determine the samples were examined. Subsequently, a form was designed consisting of multiple pieces of necessary information for the studies (investigator's name, title, year, location, the number of samples, the total prevalence of the study based on various criteria, and the patients' mean age and body mass index). Next, the basic data for this study were entered in the chart to be analyzed. The full text of the articles was examined for the analysis.

\section{Statistical Analysis}

Given that the rate of autism and concentration of elements (copper, mercury, and lead), as well as the number of samples in each article, were extracted. Variance of each study was calculated according to the binomial distribution. Studies were combined based on their sample sizes, means and standard deviations. The difference between the average variance of normal distribution was calculated using the formula of two integrated variances. Due to the heterogeneity in the studies, random effects model was used in combining studies and Cochrane Q test and $\mathrm{I}^{2}$ statistics were used. P-value less than 0.05 were considered as a significant Heterogeneity test. The average variance was calculated using the formula of two integrated variance. The mean difference was computed using the formula $d=\frac{\bar{x}_{1-\bar{x}_{2}}}{s}$, in which $\bar{x}_{1}$ is the case mean, $\bar{x}_{2}$ is the control mean, $\mathrm{s}$ is the pooled sample standard deviation defined as $\mathrm{s}=\sqrt{s^{2}}$. Where it is calculated using $s^{2}=\frac{\left(n_{1}-1\right) s_{1}^{2}-\left(n_{2-}-1\right) s_{2}^{2}}{n_{1}-n_{2}}$ were the variances of the case group and control groups, respectively, $\mathrm{n}_{1}$ and $\mathrm{n}_{2}$ equals the number of participants in each group.

Statistical analyses were performed using STATA version 12 . 


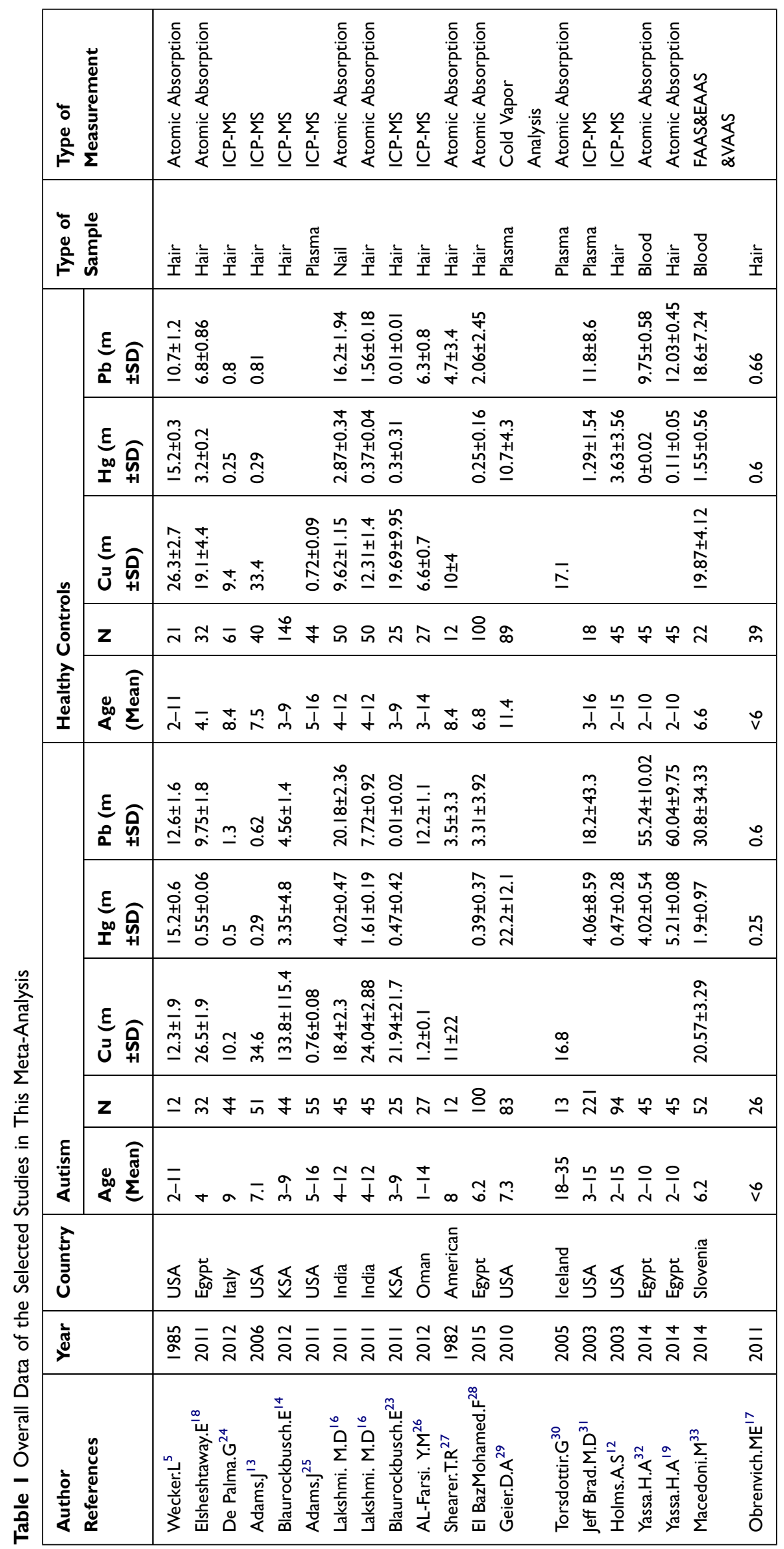


Table 2 The Relationship Between the Concentrations of Copper, Lead, and Mercury and Autism in Terms of Number and Type of Studies Included in the Meta-Analysis

\begin{tabular}{|c|c|c|c|c|c|c|}
\hline Element & Subgroup & NO. of Date from Studies & $I^{2}$ & $\operatorname{SMD}(95 \% \mathrm{Cl})$ & $P$ value for Significant & $\mathbf{Z}$ \\
\hline \multirow[t]{4}{*}{ Sample CU } & Serum and plasma & $\mathrm{I}$ & $0.000 \%$ & $0.47(0.07,0.87)$ & 0.021 & 2.31 \\
\hline & Blood & I & $0.000 \%$ & $0.20(-0.30,0.70)$ & 0.439 & 0.77 \\
\hline & Hair & 8 & $97.8 \%$ & $-0.75(-2.29,0.80)$ & 0.344 & 0.95 \\
\hline & Nail & I & $0.000 \%$ & $4.91(4.10,5.72)$ & 0.000 & 11.84 \\
\hline \multirow[t]{4}{*}{ Sample Hg } & Serum and Plasma & 2 & $90.2 \%$ & $0.83(-0.10,1.76)$ & 0.082 & 1.74 \\
\hline & Blood & 2 & $99.3 \%$ & $5.43(-4.48,15.35)$ & 0.283 & 1.07 \\
\hline & Hair & 7 & $98.9 \%$ & $1.74(-0.64,4.12)$ & 0.152 & 1.43 \\
\hline & Nail & I & $0.000 \%$ & $2.83(2.26,3.40)$ & 0.000 & 9.69 \\
\hline \multirow[t]{4}{*}{ Sample Pb } & Serum and Plasma & I & $0.00 \%$ & $0.15(-0.33,0.63)$ & 0.532 & 0.62 \\
\hline & Blood & 2 & $99.0 \%$ & $3.40(-2.47,9.27)$ & 1.13 & 0.257 \\
\hline & Hair & 8 & $98.1 \%$ & $3.18(1.47,4.89)$ & 3.65 & 0.000 \\
\hline & Nail & I & $0.000 \%$ & I.85(I.37,2.33) & 7.52 & 0.000 \\
\hline
\end{tabular}

For sensitivity analysis we did analysis with outlier and without outlier studies. Sensitivity analysis shows that there was not any influential study to change the results essentially (referred to part B each fig). Depending on the analyzed data, usually need to determine publication bias and drawing the Beggs funnel plot.

\section{Results}

The present study systematically reviewed 18 articles conducted from 1982 to 2019, in which 1797 patients (981 cases and 816 controls) aged 2 to 16 years were examined. Average concentrations of copper, mercury and lead in samples of hair, nails, and plasma of the children with autism and a control group in studies included in the metaanalysis are presented in Table 1.

Of the 18 articles included in the study, 13 articles were on hair samples, 1 article was on nail samples, 3 articles were on plasma samples, and 2 articles were on blood samples. Table 2 shows that there was no significant relationship found in hair and blood samples; however, a significant relationship was found in studies with plasma and nail samples (Table 2).

The highest concentrations of copper, lead and mercury in children with autism were respectively reported in studies by Blaurock-Bush et al in the US (133.8 \pm 1154 in the hair sample), Geier et al in the US $(22.2 \pm 12.1$ in the plasma sample), and Yassa (2014) in Egypt (60.04 \pm 9.75 in the hair sample). The lowest levels of concentrations of copper, lead and mercury in children with autism were, respectively, reported in studies by Adams (2011) in the US (0.76 \pm 0.08 in the nail sample), Obrenvich (2012) (0.25 in the hair sample), and Blaurock-Bush et al in the US $(0.01 \pm 0.02$ in the hair sample) .

\section{Copper}

The results of the study indicate that there was no significant relationship between copper concentration and autism (SMD (95\% CI): 0.02 (-1.16, 1.20); I2=97.7\%; P=0.972) (Figure 2A.Cu).

$\mathrm{CU}$ concentrations were measured in serum and plasma, blood, hair and toenails. There are differences between sample source concentrations in the studies.

Subgroups analysis showed that there are significant relationship between serum and plasma concentration 0.47 (95\% CI: 0.07-0.87) and nail 4.91 (95\% CI: 4.10-5.72) with autism, which means concentration in children with autism was higher than the concentration of $\mathrm{CU}$ in the control group. In blood 0.20 (95\% CI: $-0.30-0.70)$ and hair -0.75 (95\% CI: $-2.29-0.80)$ no significant relationship (Table 2).

Sensitivity analysis showed that by carrying out the sensitivity analysis and removing the studies demonstrating significantly different results, this result is significant (Figure 2B.Cu). The result of the publication bias figure also indicated that there was no error $(\mathrm{P}=0.413)$ (Figure 2C.Cu).

\section{Mercury}

There was a significant relationship between mercury concentration and autism (SMD (95\% CI): $1.96(0.56-3.35)$; $\mathrm{I}^{2}=98.6 \% ; \mathrm{P}=0.006$ ) (Figure 3A.Hg). 
A

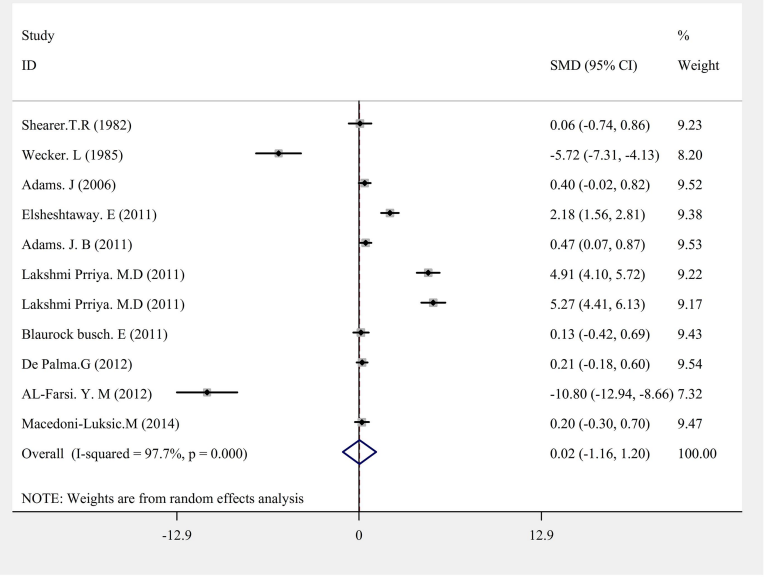

B Meta-analysis estimates, given named study is omited

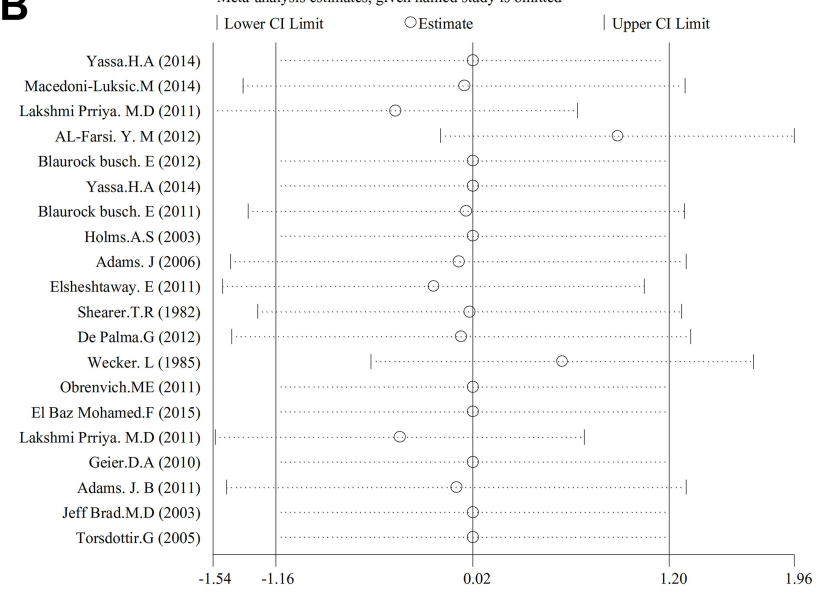

C

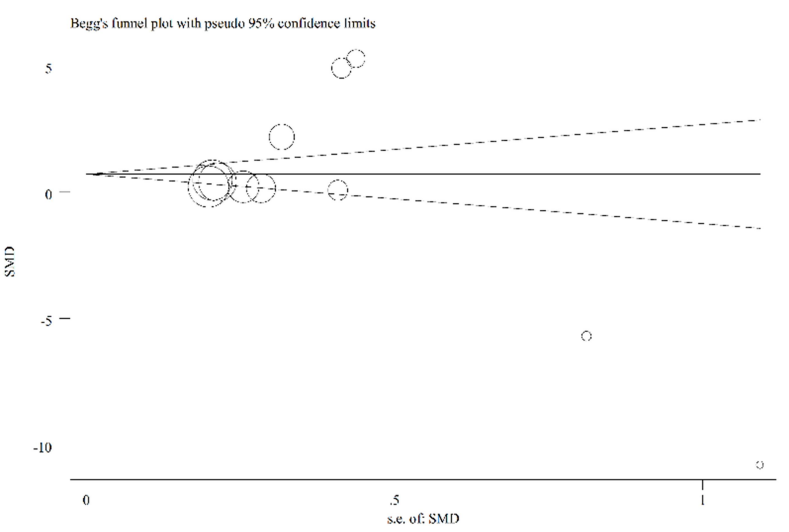

Figure 2 (A) cu Forest plots for the studies Cu concentration statuses combination difference between autistic patients and healthy individuals. The area of each square is proportional to the percentage weight of each individual study in the meta-analysis ( $\mathrm{Cl} 95 \%)$. In this chart, studies are stored in order of year publication and author's names, based on a random effects model. (B) cu. Sensitivity analysis for studies in overall study copper for autism patients versus healthy controls. (C) cu. Begg's funnel plot for publication bias in the risk difference (RD) analysis. The diameter of each circle represents the weight in the meta-analysis.

Sensitivity analysis showed that by carrying out the sensitivity analysis and removing the studies demonstrating significantly different results, this result is also significant (Figure 3B.Hg). The result of the publication bias figure also revealed that there was no error here.

\section{Lead}

There is a significant relationship between lead concentration and autism (SMD (95\% CI): 2.81 (1.64-3.98); $\mathrm{I}^{2}=97.8 \% ; \mathrm{P}=0.000$ ) (Figure 4A.Pb). Sensitivity analysis showed that by carrying out the sensitivity analysis and removing the studies demonstrating significantly different results, this result is also significant (Figure 4B.Pb). The result of the publication bias figure showed that there was an error.

\section{Discussion}

The present study was performed using meta-analysis to investigate the concentration of copper, mercury, and lead in samples of hair, nails and plasma in 2-16-year-old samples, showing that there was no significant difference between the concentration of copper in children with autism and those of a control group (95\% CI:0.02 $(-1.16,1.20)$ ).

These results are consistent with the findings of Luksic et al and Elsheshtaway. ${ }^{18,19}$ On the other hand, Lakshmi Priya and Geetha (2011) found that levels of copper concentration in hair and nail samples of the children with different degrees of autism severity showed a high statistical difference compared to those of the control group. ${ }^{18}$ Weker et al found that the mean copper concentration (ppm) in the hair of children with autism was lower than that of the control group $(12,3$ vs. 26,3$) .^{5}$ 
A

Study

ID

Wecker. L (1985)

Holms.A.S (2003)

Jeff Brad.M.D (2003)

Geier.D.A (2010)

Lakshmi Prriya. M.D (2011)

Blaurock busch. E (2011)

Elsheshtaway. E (2011)

Lakshmi Prriya. M.D (2011)

Yassa.H.A (2014)

Macedoni-Luksic.M (2014)

Yassa.H.A (2014)

El Baz Mohamed.F (2015)

Overall $($ I-squared $=98.6 \%, \mathrm{p}=0.000)$

NOTE: Weights are from random effects analysis

$-87.8$
SMD $(95 \%$ CI $) \quad$ Weight

$0.00(-0.71,0.71) \quad 9.29$

$-1.56(-1.96,-1.16) \quad 9.44$

$0.33(-0.15,0.82) \quad 9.41$

$1.28(0.96,1.61) \quad 9.46$

$9.26(7.87,10.65) \quad 8.69$

$0.46(-0.10,1.02) \quad 9.37$

$-17.95(-21.14,-14.75) 6.34$

$2.83(2.26,3.40) \quad 9.36$

$10.52(8.91,12.13) \quad 8.44$

$0.40(-0.10,0.90) \quad 9.40$

$\longrightarrow 76.45(65.15,87.75) \quad 1.31$

$0.49(0.21,0.77) \quad 9.48$

$1.96(0.56,3.35) \quad 100.00$

B

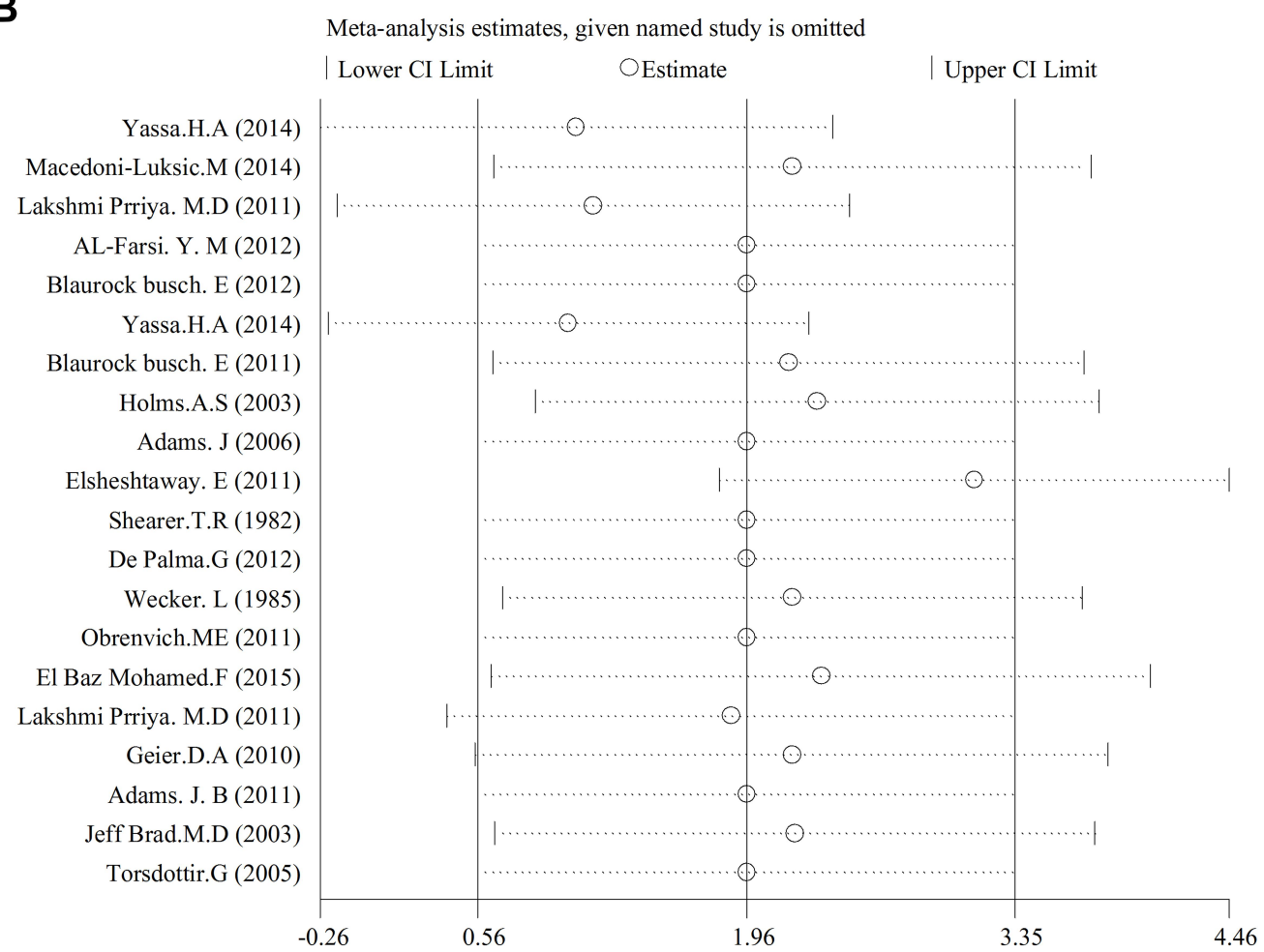

Figure $3(\mathbf{A}) \mathrm{Hg}$, Forest plots for the studies $\mathrm{Hg}$ statuses combination difference between autistic patients and healthy individuals. The area of each square is proportional to the percentage weight of each individual study in the meta-analysis (Cl 95\%). In this chart, studies are stored in order of year publication and author's names, based on a random effects model. (B) $\mathrm{Hg}$. Sensitivity analysis for studies in overall study for autism patients versus healthy controls. 
A

Study

ID
$\%$

SMD $(95 \%$ CI $) \quad$ Weight

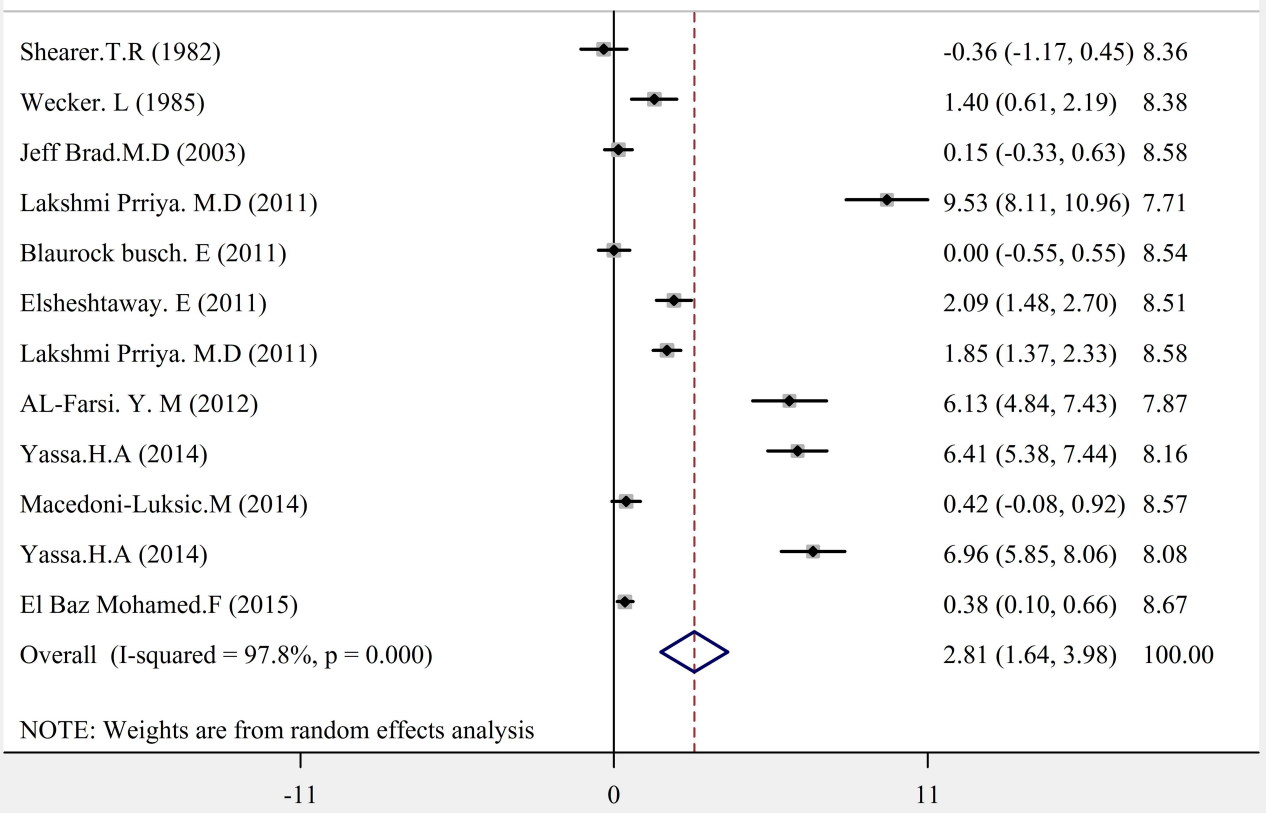

B

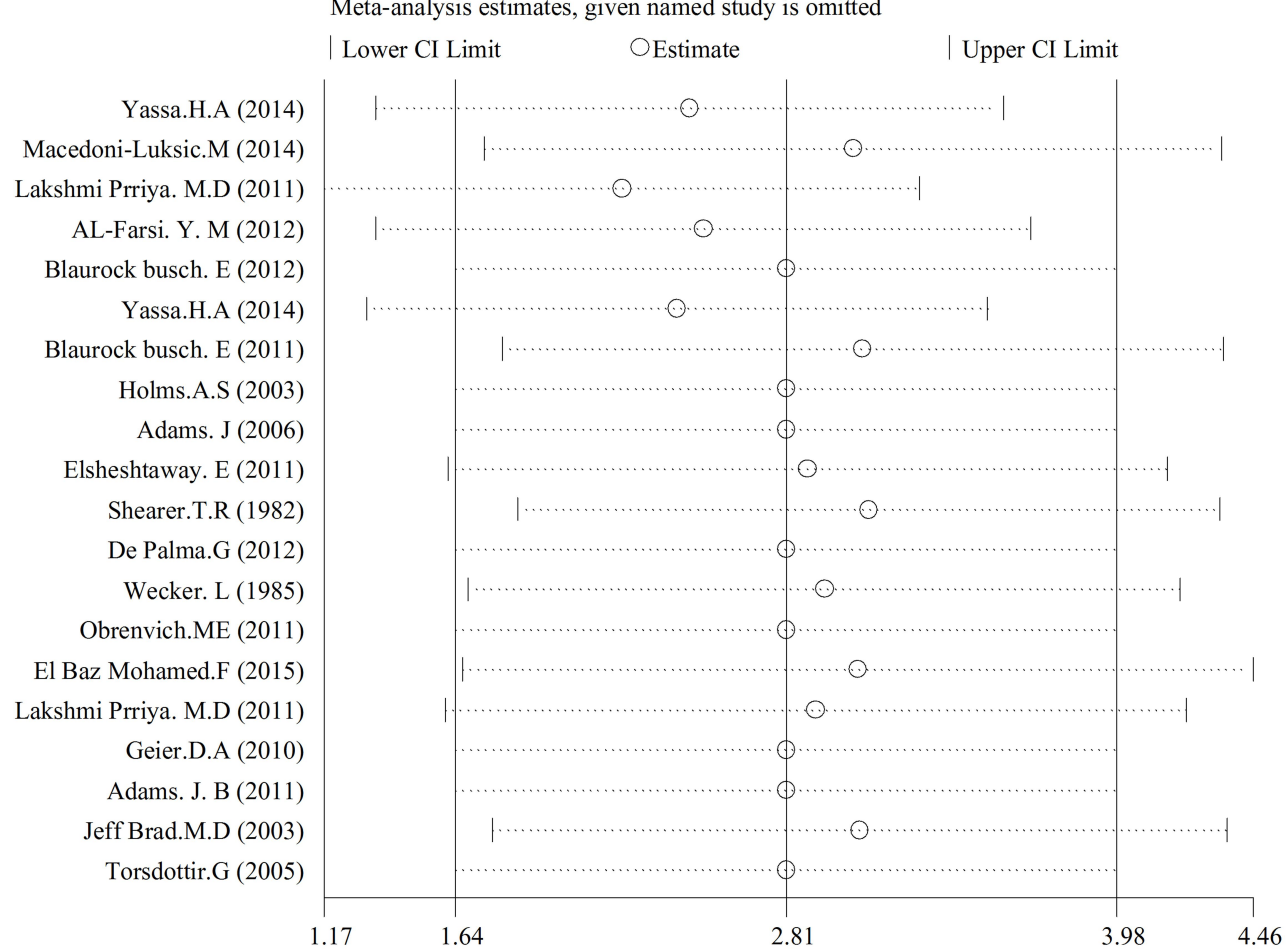

Figure 4 (A) Pb. Forest plots for the studies $\mathrm{Pb}$ statuses combination difference between autistic patients and healthy individuals. The area of each square is proportional to the percentage weight of each individual study in the meta-analysis (Cl 95\%). In this chart, studies are stored in order of year publication and author's names, based on a random effects model. (B) Pb. Sensitivity analysis for studies in overall study for autism patients versus healthy controls. 
The difference in results could be due to differences in methods of measuring the concentration of copper, mercury, and lead and the amount of children's exposure to the elements before and after their birth. In this study, there was a significant relationship between the concentration of mercury in plasma samples and nails and autism $(95 \% \mathrm{CI}$ : $1.96(0.56,3.35))$. This result shows that heavy elements are directly related to the incidence of diseases, such as autism. This finding is in agreement with the results of other studies. $^{3,4,7,14,17,18,20-22}$

The results of the present study revealed that there is a significant relationship between lead concentration and autism $(95 \%$ CI: $2.81(1.64,3.98))$. This finding is also line with the results of other studies. ${ }^{4,5,7,18,20-23}$

Human hair accurately evaluated for trace element value regarding observing either the environmental-occupational exposure to toxic metals level of body upon long exposure duration. In a study by Elsheshtaway, lead concentration in the hair of children with autism $(9.75 \pm 1.8 \mathrm{ug} /$ $\mathrm{mg}$ ) was higher than the concentration of lead in the control group $(6.8 \pm 0.86 \mathrm{ug} / \mathrm{mg}){ }^{18,24}$

Adams et al study discuss about the role of age and autistic children are exposed to toxic metals. In this study, the amount of mercury level was $0.21 \mu \mathrm{g} / \mathrm{g}$ (age 3-6 years), also in NHANES study (1999-2000) of 838 children (1-6 years) $0.12 \mu \mathrm{g} / \mathrm{g}$ reported.

According to points raised in the present study about the relationship between copper, mercury, and lead (risk factors) and the development of autism, it would be quite reasonable to advise prevention of exposure to mercury and lead in children and provision of suitable conditions during the sensitive period of mothers' pregnancy as vital measures to prevent the disease from infecting the children. The main limitation of this meta-analysis study was the high heterogeneity among the studies. Random effects model was a way to reduce this heterogeneity. Some other limitations and weaknesses of the study include:

1. The absence of an identical method to measure the variance.

2. Lack of information about the participants' nutrition and lifestyle

3. Diversity of screening methods and lack of a standard unit to measure the concentration of elements in various articles.

4. Lack of access to some relevant studies

\section{Conclusion}

According to the results of this study, there is no significant relationship between copper and lead concentration and the development of autism. There is, nevertheless, a significant relationship between mercury concentration and autism. Thus, the concentration of mercury can be listed as a pathogenic cause (disease-causing) for autism.

\section{Acknowledgments}

The authors extend their gratitude to the Arak University of Medical Science.

\section{Author Contributions}

All authors contributed to data analysis, drafting or revising the article, gave final approval of the version to be published, and agree to be accountable for all aspects of the work.

\section{Disclosure}

The authors report no benefits in any form have been or will be received from a commercial party related directly or indirectly to the subject of this article. The authors report no conflicts of interest for this work.

\section{References}

1. Kinney DK, Munir KM, Crowley DJ, Miller AM. Prenatal stress and risk for autism. Neurosci Biobehav Rev. 2008;32(8):1519-1532.

2. Bailey A, Phillips W, Rutter M. Autism: towards an integration of clinical, genetic, neuropsychological, and neurobiological perspectives. J Child Psychol Psychiatry. 1996;37(1):89-126. doi:10.1111/ j.1469-7610.1996.tb01381.x

3. Kaushik G, Huber DP, Aho $\mathrm{K}$, et al. Maternal exposure to Carbamazepine at environmental concentrations can cross intestinal and placental barriers. Biochem Biophys Res Commun. 2016;474 (2):291-295. doi:10.1016/j.bbrc.2016.04.088

4. Bernard S, Enayati A, Redwood L, Roger H, Binstock T. Autism: a novel form of mercury poisoning. Med Hypotheses. 2001;56(4):462471. doi:10.1054/mehy.2000.1281

5. Wecker L, Miller SB, Cochran SR, et al. Trace element concentrations inhair from autistic children. J Ment Defic Res. 1985;29:15-22.

6. Grandjean P, Landrigan PJ. Developmental Neurotoxicity of IndustrialChemicals. Lancet. 2006;368:2167-2178. doi:10.1016/ S0140-6736(06)69665-7

7. Lonsdale D, Shamberger RJ, Audhya T. Treatment of autism spectrum children with thiamine tetrahydrofurfuryl disulfide: a Pilot Study. Neuroendocrinol. 2002;23:303-308.

8. Priya MD, Geetha A. Level of trace elements (copper, zinc, magnesium and selenium) and toxic elements (lead and mercury) in the hair and nail of children with autism. Biol Trace Elem Res. 2010;111.

9. Bernard S, Enayati A, Roger H, et al. The role of mercury in the pathogenesis of autism. Mol Psych. 2002;7:542-543. doi:10.1038/sj. mp.4001177 
10. Yorbik O, Kurt I, Hasimi A, et al. Chromium, cadmium, and lead levels in urine of children with autism and typically developing Controls. Biol Trace Elem Res. 2010;135:10-15. doi:10.1007/ s12011-009-8494-7

11. Geier DA, King PG, Sykes LK, Geier MR. A comprehensive review of mercury provoked autism. Indian J Med Res. 2008;12 $8: 383-411$.

12. Holmes AS, Blaxill MF, Haley BE. Reduced levels of mercury in first baby haircuts of autistic children. Int J Toxicol. 2003;22(4):277-285. doi:10.1080/10915810305120

13. Adams JB, Romdalvik J, Ramanujam VM, Legator MS. Mercury, lead, and zinc in baby teeth of children with autism versus controls. $J$ Toxicol Environ Health A. 2007;70(12):1046-1051. doi:10.1080/ 15287390601172080

14. Blaurock-Busch E, Amin OR, Dessoki HH, Rabah T. Toxic metals and essential elements in hair and severity of symptoms among children with autism. J Clin Med. 2012;7(1):38-48.s.

15. Underwood EA. Trace Elements in Human and Animal Nutrition (Fourth Edition). New York, NY: Academic Press; 1977.

16. Lakshmi Priya MD, Geetha A. Level of trace elements (copper, zinc, magnesium and selenium) and toxic elements (lead and mercury) in the hair and nail of children with autism. Biol Trace Elem Res. 2011;142(2):148-158. doi:10.1007/s12011-010-8766-2

17. Cohen DJ, Johnson WT, Caparulo BK. Pica and elevated blood lead level in autistic and atypical children. Am J Dis Child. 1976;130:4748. doi:10.1001/archpedi.1976.02120020049007

18. Elsheshtawy E, Tobar S, Sherra K, Atallah S, Elkasaby R. Study of some biomarkers in hair of children with autism. Institute Psychiatry Ain Shams Univ. 2011;18:6-10.

19. Macedoni-Lukšič M, Gosar D, Bjørklund G, et al. Levels of Metals in the Blood and Specific Porphyrins in the Urine in Children with Autism Spectrum Disorders. New York: Springer Science+Business Media; 2014.

20. Kumar A, Dey PK, Singla PN. Blood lead levels in children with neurological disorders. J Trop Pediatr. 1998;44:320-322. doi:10.1093/tropej/44.6.320

21. AL-Ayadhi L. Heavy metals and trace elements in hair samples of autistic and normal children in central Saudi Arabia. Neurosci. 2005;10:213-218.

22. Goyer RA. Toxic and essential metal interactions. Ann Rev Nutr. 1997;17:37-50. doi:10.1146/annurev.nutr.17.1.37
23. Blaurock-Busch E, Amin OR, Rabah T. Heavy metals and trace elements in hair and urine of a sample of Arab children with autistic spectrum disorder. J Clin Med. 2011;6(4):247.

24. De Palma G, Catalani S, Franco A, Brighenti M, Apostoli P. Lack of correlation between metallic elements analyzed in hair by ICP-MS and autism. J Autism Dev Disord. 2012;42(3):342-353. doi:10.1007/ s10803-011-1245-6

25. Adams JB 1*, Audhya T 2, McDonough-Means S3, et al. Nutritional and metabolic status of children with autism vs. neurotypical children, and the association with autism severity. Nutr Metab. 2011;8:34. doi:10.1186/1743-7075-8-34

26. Al-Farsi YM, Waly MI, Al-Sharbati MM, et al. Levels of Heavy Metals and Essential Minerals in Hair Samples of Children with Autism in Oman: A Case-Control Study. New York: Springer Science+Business Media; 2012.

27. Shearer TR, Larson K, Neuschwander J, Gedney B. Minerals in the hair and nutrient intake of autistic children. $J$ Autism Dev Disord. 1982;12(1):25-34. doi:10.1007/BF01531671

28. Mohamed FEB 1, Zaky EA 1, El-Sayed AB 2, et al. Assessment of hair aluminum, lead, and mercury in a sample of autistic Egyptian children: environmental risk factors of heavy metals in autism. Behav Neurol. 2015;2015:1-9. doi:10.1155/2015/545674

29. Geier DA 1,2, Audhya T 3, Kern JK 4,5, Geier MR. Blood mercury levels in autism spectrum disorder: is there a threshold level? Acta Neurobiol Exp. 2010;70:177-186.

30. Tórsdóttir G, Hreidarsson S, Kristinsson J, Snaedal J, Jóhannesson T. Ceruloplasmin, superoxide dismutase and copper in autistic patients. Basic Clin Pharmacol Toxicol. 2005;96:146-148. doi:10.1111/j.17427843.2005.pto960210.x

31. Bradstreet J, Geier DA, Kartzinel JJ, Adams JB, Geier MR. A casecontrol study of mercury burden in children with autistic spectrum disorders. J Am Physicians Surg. 2003;8(3):76-79.

32. Yassa HA. Autism: a form of lead and mercury toxicity. Environ Toxicol Pharmacol. 2014;1-29.

33. Obrenovich ME, Shamberger RJ, Lonsdale D. Altered Heavy Metals and Transketolase Found in Autistic Spectrum Disorder. Springer Science+Business Media, LLC; 2011.
Pediatric Health, Medicine and Therapeutics

\section{Publish your work in this journal}

Pediatric Health, Medicine and Therapeutics is an international, peerreviewed, open access journal publishing original research, reports, editorials, reviews and commentaries. All aspects of health maintenance, preventative measures and disease treatment interventions are addressed within the journal. Practitioners from all disciplines are invited to submit their work as well as healthcare researchers and patient support groups. The manuscript management system is completely online and includes a very quick and fair peer-review system. Visit http://www.dovepress.com/testimonials.php to read real quotes from published authors. 